\title{
Learning Curve of Endoscopic Retrograde Cholangiopancreatography Using Single-Balloon Enteroscopy
}

\author{
Kunihiro Hosono ${ }^{1}$ (D) Takamitsu Sato ${ }^{1} \cdot$ Sho Hasegawa ${ }^{1}$. Yusuke Kurita ${ }^{1}$ Shin Yagi ${ }^{1}$. Akito Iwasaki ${ }^{2} \cdot$ Yuji Fujita $^{3}$. \\ Yusuke Sekino ${ }^{4}$. Emiko Tanida ${ }^{5}$. Takaomi Kessoku ${ }^{1}$ - Shingo Kato ${ }^{1} \cdot$ Takuma Higurashi $^{1} \cdot$ Masato Yoneda $^{1}$. \\ Kensuke Kubota ${ }^{1} \cdot$ Atsushi Nakajima $^{1}$
}

Received: 12 July 2021 / Accepted: 11 November 2021 / Published online: 1 January 2022

(c) The Author(s) 2021

\begin{abstract}
Background Endoscopic retrograde cholangiopancreatography (ERCP) in patients with surgically altered anatomy is technically difficult. Extensive training is required to develop the ability to perform this procedure.

Aims To investigate the learning curve of single-balloon-assisted enteroscopy ERCP (SBE-ERCP).

Methods We conducted a retrospective, observational case series at a single center. We evaluated the SBE-ERCP procedures between April 2011 and February 2021. The main outcomes were the rate of reaching the target site and the success rate of the entire procedure. These parameters were additionally expressed as a learning curve.

Results A total of 687 SBE-ERCP procedures were analyzed. The learning curve was analyzed in blocks of 10 cases. In this study, seven endoscopists, experts in conventional ERCP, were included. The overall SBE-ERCP procedural success rate was 92.2\% (634/687 cases). Combining all data from individual endoscopists' evaluation periods, the insertion and success rates of the SBE-ERCP procedures gradually increased with increased experience performing SBE-ERCP. The insertion success rates for the number of SBE-ERCP cases $(<20,21-30,>30)$ were $82.9 \%, 92.9 \%$, and $94.3 \%$, respectively; the procedure success rates were $74.3 \%, 81.4 \%$, and $92.9 \%$, respectively. The endoscopists who had performed $>30$ SBE-ERCP cases had a success rate of $\geq 90 \%$.

Conclusions Our results suggest that performing $>30$ cases is one of the targets for conventional ERCP experts to become competent in performing SBE-ERCP in patients with a surgically altered anatomy.
\end{abstract}

Keywords Learning curve $\cdot$ Single-balloon-assisted enteroscopy $\cdot$ Endoscopic retrograde cholangiopancreatography ·

Surgically altered anatomy

An editorial commenting on this article is available at https://doi. org/10.1007/s10620-021-07348-w.

Kunihiro Hosono

hiro1017@yokohama-cu.ac.jp

1 Division of Gastroenterology and Hepatology, Yokohama City University Hospital, 3-9 Fukuura, Kanazawa-ku, Yokohama 2360004, Japan

2 Gastroenterology Division, Yokohama Sakae Kyosai Hospital, Yokohama, Japan

3 Department of Hepato-Biliary-Pancreatic Medicine, NTT Medical Center Tokyo, Tokyo, Japan

4 Department of Gastroenterology, Yokohama Rosai Hospital, Yokohama, Japan

5 Department of Gastroenterology, Machida Municipal Hospital, Tokyo, Japan

\section{Introduction}

Endoscopic retrograde cholangiopancreatography (ERCP) is an important procedure in the treatment of pancreatic and biliary diseases. The ERCP success rate is approximately $90-95 \%$ in patients with normal gastrointestinal anatomy [1]. However, performing ERCP using conventional endoscopes is technically difficult and often unsuccessful in patients with a surgically altered anatomy. The ERCP success rate in patients with a surgically altered anatomy is lower than that in patients with normal anatomy $[2,3]$ because it is difficult to reach the target site, such as the bile duct jejunal anastomosis, through the long limb after digestive tract reconstruction [4-8].

Balloon-assisted enteroscopy is an effective technique for deep insertion in the small intestine. The first 
balloon-assisted enteroscopy, termed ERCP (BAE-ERCP), was reported in 2005 by Haruta et al., who performed ERCP and treated an anastomotic stricture in a patient with Roux-en-Y gastrectomy [9]. Subsequently, the ERCP technique for patients with a surgically altered gastrointestinal anatomy has advanced dramatically, and good outcomes of BAE-ERCP have been reported [10-13]. The success rates of reaching the target site and ERCP-related procedures are $73-100 \%$ and $85-100 \%$, respectively $[14,15]$. Although the demand for the BAE-ERCP procedure is increasing, it requires a high level of skill and is not yet a routine procedure that can be performed in any facility. Therefore, extensive training is required to develop the ability to perform this procedure. According to the guidelines of the American Society for Gastrointestinal Endoscopy, to achieve competency in ERCP with normal anatomy and learn basic skills, trainees should perform at least 200 ERCP procedures [16]. However, the number of BAE-ERCP procedures required to attain learner competency is unknown. Regarding BAEERCP procedures, various techniques are required to achieve complete procedural success, such as endoscope insertion, cannulation, stone removal, and stent insertion, among others. Currently, few studies have evaluated the learning curves and competence in BAE-ERCP procedures regarding these relevant endpoints. This study aimed to investigate the learning curve of the BAE-ERCP procedure. This study examined the learning curve of single-balloon-assisted enteroscopy ERCP (SBE-ERCP) because our institution has only single-balloon enteroscopy (SBE) as a balloon-assisted enteroscopy for ERCP.

\section{Materials and Methods}

\section{Study Design}

This study was a retrospective, observational case series that included patients who were treated at the endoscopy center of Yokohama City University Hospital (YCUH), a tertiary referral teaching hospital in Yokohama, Japan. This study complied with the Declaration of Helsinki and was approved by the Research Ethics Committee of The Yokohama City University (Approval number: B191200004). The study was registered at University Hospital Medical Network Clinical Trials Registry with clinical trial number UMIN000043441.

On average, 800 ERCP procedures are performed each year at the center. Information on the SBE-ERCP procedure data was retrieved from our unit database between April 2011 and February 2021. Information on patient characteristics, history of gastrointestinal tract surgery, indications, success in reaching the target site, insertion time, findings, and interventions using SBE-ERCP, procedure outcome, overall procedure time, and adverse events were all retrieved from the clinical records.

\section{Patients}

Patients with surgically altered gastrointestinal anatomy who were referred for SBE-ERCP for a broad range of indications such as obstructive jaundice, bile duct stones, biliary stricture, stricture of bile duct jejunal anastomosis, pancreatic indication, and others were included. From all patients, written informed consent was obtained prior to the procedure.

\section{SBE-ERCP Procedure}

Seven expert endoscopists with no prior SBE-ERCP experience participated in the study. At our facility, the same endoscopist inserted the endoscope and performed the ERCP procedures. In each case, the endoscopic procedure was performed by the patient's attending physician. They had performed $>400$ conventional ERCPs in patients with normal anatomy and $>300$ colonoscopies before the present study. Only one endoscopist had experienced about 10 cases of conventional balloon enteroscopy beforehand, but the other endoscopists had no experience. These also include experience with other institutions. Each SBE-ERCP procedure was performed using SIF-Q260 (working channel diameter, $2.8 \mathrm{~mm}$; working length, $200 \mathrm{~cm}$; Olympus Medical Systems, Tokyo, Japan). During the procedure, all patients were consciously sedated and carbon dioxide gas insufflation was used through the endoscope. A disposable distal attachment (D-201-10704; Olympus) was attached to the enteroscope tip. When the endoscope reached a bifurcation point such as the Brown anastomosis, it was marked with a clip (EZ clip; Olympus) as a landmark. After the endoscope reached the target site, such as the papilla, cannulation into the biliary or pancreatic duct was tried using an ERCP catheter (tapered tip $250 \mathrm{~cm}$; MTW-Endoskopie, Wesel, Germany).

\section{Main Outcome Measures}

The primary outcomes were the rate of endoscope insertion and the success rate of the entire procedure of SBE-ERCP. These parameters were additionally expressed as a learning curve. Endoscope insertion success was defined as successful arrival at the target site using an SBE. Cannulation success was defined as successful cannulation into the target duct to obtain cholangiography and/or pancreatography. Procedural success was defined as successful diagnostic and therapeutic interventions, such as stent insertion/removal, stone extraction, pancreaticobiliary duct dilation, sphincterotomy, and anastomotic dilation, among others. If the endoscope insertion or procedure had failed for $30 \mathrm{~min}$, a different endoscopist continued the procedure; if this procedure 
was successful, the learning curve evaluation defined the procedure as having failed. The secondary outcome was the incidence of adverse events. Adverse events were assessed according to the American Society for Gastrointestinal Endoscopy severity grading system [17]. Adverse events were documented based on a review of the medical record.

\section{Statistical Analysis}

Results are shown as means [ \pm standard deviations (SDs)] for quantitative variables, medians (range) for nonparametric variables, and percentages for categorical variables. Categorical variables were analyzed using Fisher's exact test. The Tukey-Kramer test was used as a multiple comparison test. The learning curve analysis was performed separately for each endoscopist. The data for each endoscopist were analyzed in blocks of 10 cases, based on the methods of past study [18]. The data were plotted against time, and we tested the trend of the success rate in each block using logistic regression analysis. The proportion of complications between patients who underwent each surgical gastrointestinal reconstruction and those who underwent other reconstructions was examined with a Chi-square test. All statistical analyses were performed using JMP Pro 15.0 software program (SAS institute, Japan). A $P$ value of $<0.05$ indicated a statistically significant difference.

\section{Results}

\section{Demographics}

A total of 687 procedures were performed with SBE-ERCP. The mean $( \pm$ SD) age was $69.9( \pm 13.1)$ years, and 500 patients were male (72.7\%). The demographic and clinical characteristics of all patients are shown in Table 1. The most common reconstruction technique was hepaticojejunostomy with Roux-en-Y gastrectomy (HJ), performed in 335 patients (48.8\%), followed by pancreaticoduodenectomy (PD) in 161 patients (23.4\%), Roux-en-Y gastrectomy (R-Y) in 122 patients (17.8\%), and Billroth-II gastrectomy with Brown anastomosis (B-II) in 52 patients (7.6\%). Of the 122 patients who underwent R-Y gastrectomy, 120 had gastric cancer and the remaining 2 had gastroduodenal ulcer. Other techniques in 17 patients $(2.5 \%)$ included gastrojejunal bypass (14 patients) and the Imanaga method (three patients). Moreover, there were no patients who underwent gastric bypass surgery. The most common indication that led to SBE-ERCP was bile duct stones (39.8\%), followed by obstructive jaundice $(20.5 \%)$ and stricture of bile duct jejunal anastomosis $(20.5 \%)$.
Table 1 Patient characteristics

\begin{tabular}{ll}
\hline Age, mean (range), years & $69.9( \pm 13.1)$ \\
Sex (male/female), $n$ & $500 / 187$ \\
Surgical reconstruction methods, $n(\%)$ & \\
Roux-en-Y gastrectomy (R-Y) & $122(17.8)$ \\
Billroth-II gastrectomy (B-II) & $52(7.6)$ \\
Pancreaticoduodenectomy (PD) & $161(23.4)$ \\
Hepaticojejunostomy with Roux-en-Y (HJ) & $335(48.8)$ \\
Others & $17(2.5)$ \\
Indication, $n(\%)$ & \\
Obstructive jaundice & $141(20.5)$ \\
Bile duct stones & $273(39.8)$ \\
Biliary stricture & $51(7.5)$ \\
Stricture of bile duct jejunal anastomosis & $141(20.5)$ \\
Pancreatic indication & $68(9.9)$ \\
Others & $13(1.9)$ \\
\hline
\end{tabular}

\section{Outcomes of SBE-ERCP}

Results of SBE-ERCP procedures are summarized in Table 2. The overall success rate of endoscope insertion was $94.6 \%$ (650/687 cases). The percentage of patients who had undergone R-Y, B-II, PD, HJ, and other reconstruction techniques were 96.7, 98.1, 96.9, 91.9, and 100\%, respectively. Overall mean insertion time was $22.1 \mathrm{~min}$ (range 3-79 $\mathrm{min}$ ), and there was no significant difference according to structural anatomies. The overall cannulation success rate was $93.3 \%$ (641/687 cases). The overall success rate of the entire procedure was $92.2 \%(634 / 687$ cases). According to the reconstruction technique, the percentage of patients who had undergone R-Y, B-II, PD, HJ, and other reconstruction techniques were $93.4 \%, 96.2 \%$, $94.4 \%, 89.9 \%$, and $100 \%$, respectively. The success rate of procedures performed by a single endoscopist was $83.5 \%$ (574/687 cases). Then, 113 cases were switched to another endoscopist to continue the procedure, and $60 / 113$ cases $(53.1 \%)$ were successful. The overall mean procedural time was $57.3 \mathrm{~min}$ (range $12-151 \mathrm{~min}$ ). The mean procedural time was longer in R-Y than in the other groups (vs B-II; $P=0.0016$, vs $\mathrm{PD} ; P<0.0001$, vs $\mathrm{HJ}$; $P=0.0001)$. No significant differences were found in the other parameters.

In Table 3, when compared to the group with native papilla (R-Y and B-II) and bilioenteric anastomosis (PD and $\mathrm{HJ}$ ), the success rate of cannulation and the entire procedure of SBE-ERCP were not significantly different. On the other hand, entire procedural time of the native papilla group was longer than that of the other groups.

The outcomes of the 53 unsuccessful procedures were as follows: 25 cases underwent follow-up or conservative treatment, 10 cases underwent additional percutaneous 
Table 2 Overall procedural success of SBE-ERCP
Table 3 Comparison of results between groups with native papilla and bilioenteric anastomosis

\begin{tabular}{lllllll}
\hline & Total & RY & B-II & PD & HJ & Others \\
& $n=687$ & 122 & 52 & 161 & 335 & 17 \\
\hline Endoscope insertion success, $n(\%)$ & $650(94.6)$ & $118(96.7)$ & $51(98.1)$ & $156(96.9)$ & $308(91.9)$ & $17(100)$ \\
Insertion time, Mean (min) & 22.1 & 23.7 & 21.9 & 19.4 & 23.2 & 18.5 \\
Cannulation success, $n(\%)$ & $641(93.3)$ & $115(94.3)$ & $50(96.2)$ & $153(95.0)$ & $306(91.3)$ & $17(100)$ \\
Procedural success, $n(\%)$ & $634(92.2)$ & $114(93.4)$ & $50(96.2)$ & $152(94.4)$ & $301(89.9)$ & $17(100)$ \\
Procedural time, Mean (min) & 57.3 & $71.7 *$ & 52.1 & 50.4 & 54.9 & 55.2 \\
\hline
\end{tabular}

The Tukey-Kramer test was used as a multiple comparison test

$R-Y$ Roux-en-Y gastrectomy, $B-I I$ Billroth-II gastrectomy, $P D$ pancreaticoduodenectomy, $H J$ hepaticojejunostomy with Roux-en-Y, $S B E-E R C P$ single-balloon-assisted enteroscopy endoscopic retrograde cholangiopancreatography

$* P<0.05$

\begin{tabular}{llll}
\hline & $\begin{array}{l}\text { Native papilla (RY } \\
\text { and B-II) } \\
n=174\end{array}$ & $\begin{array}{l}\text { Bilioenteric anastomosis } \\
\text { (PD and HJ) } \\
n=496\end{array}$ & 0.26 \\
\hline Cannulation success, $n(\%)$ & $165(94.8)$ & $459(92.5)$ & 0.17 \\
Procedural success, $n(\%)$ & $164(94.2)$ & $453(91.3)$ & \\
Interventions, $n(\%)$ & $<0.001^{*}$ & & \\
Stone extraction & $111(63.8)$ & $103(20.8)$ \\
Endoscopic sphincterotomy & $14(8.0)$ & $3(0.6)$ \\
Endoscopic papillary balloon dilation & $70(40.2)$ & $0(0)$ \\
Balloon dilation of stenotic anastomosis & $0(0)$ & $64(12.9)$ \\
Biliary plastic stenting & $29(16.7)$ & $125(25.2)$ \\
Biliary metallic stenting & $13(7.5)$ & $8(1.6)$ \\
Endoscopic pancreatic drainage & $6(3.4)$ & $19(3.8)$ \\
Entire procedural time, mean (min) & 66.3 & 52.9 & $<0.001^{*}$ \\
\hline
\end{tabular}

$R-Y$ Roux-en-Y gastrectomy, $B$-II Billroth-II gastrectomy, $P D$ pancreaticoduodenectomy, $H J$ hepaticojejunostomy with Roux-en-Y

$* P<0.05$

procedures, 11 cases underwent interventional-EUS procedures, and 7 cases underwent surgery.

\section{Learning Curve of SBE-ERCP}

The endoscope insertion success rate was analyzed in blocks of 10 cases. For example, the results of one endoscopist who had previously experienced a conventional enteroscopy performed were $50 \%$ ( $0-10$ cases), $80 \%$ (11-20 cases), $90 \%$ (21-30 cases), and $100 \%$ (31-40 cases). When all the endoscopist's individual data for the evaluation periods were combined, the overall success rate of the endoscope insertion had gradually increased with the total number of SBEERCP procedures performed (Fig. 1A). Logistic regression analysis showed a statistically significant improvement in endoscope insertion with increasing experience over time $(P=0.002)$. In a result of SBE-ERCP per block of 10 times, the insertion success rate was $82.9 \%$ for $11-20$ SBE-ERCPs,
92.9\% for 21-30 SBE-ERCPs, and $94.3 \%$ for $31-40$ SBEERCPs (Table 4). Thus, after $>20$ cases, the endoscope insertion success rate reached $\geq 90 \%$.

The success rate of the procedure was analyzed in blocks of 10 cases. For example, the results of one endoscopist who had previously experienced a conventional enteroscopy performed were $40 \%$ ( $0-10$ cases), $70 \%$ ( $11-20$ cases), $80 \%$ ( $21-30$ cases), and $100 \%$ ( $31-40$ cases). When all the endoscopist's individual data for the evaluation periods were combined, the overall success rate of the procedure had gradually increased with the total number of BAE-ERCPs performed (Fig. 1B). Logistic regression analysis showed a significant improvement in the procedure with increasing experience over time $(P<0.001)$. In the analysis of SBEERCP per block of 10 times, the procedural success rate was $74.3 \%$ for $11-20$ SBE-ERCPs, $81.4 \%$ for $21-30$ SBEERCPs, and 92.9\% for 31-40 SBE-ERCPs (Table 4). Thus, after $>30$ cases, the procedural success rate reached $\geq 90 \%$. 
Fig. 1 All trainee performance in SBE-ERCP. The average success rate was calculated in blocks of 10 cases. A Probability of achieving an endoscope insertion plotted against the number of SBE-ERCPs performed. B Probability of achieving a procedure plotted against the number of SBE-ERCPs performed. The solid line shows the entire group, and the dotted line shows the standard deviations +1 and -1
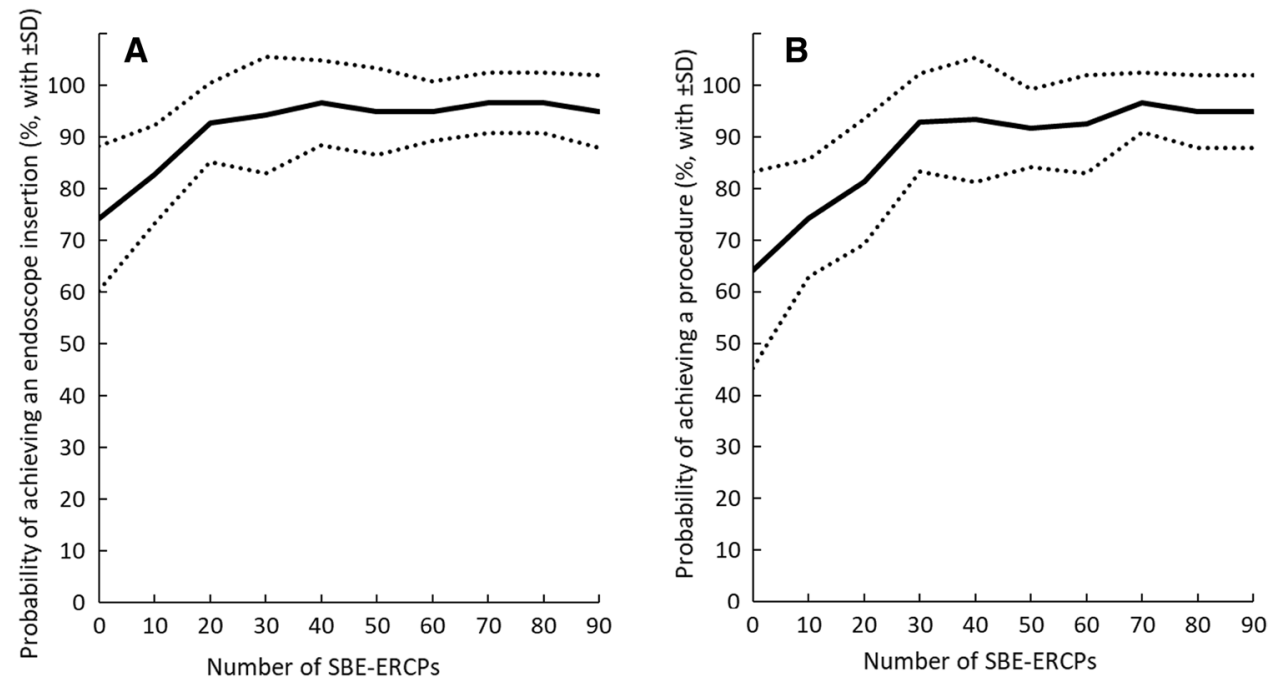

Table 4 Success rates of endoscope insertion and procedure performed by trainees for successive groups of 10 procedures

\begin{tabular}{llll}
\hline $\begin{array}{l}\text { Successive SBE- } \\
\text { ERCP blocks }\end{array}$ & Trainees, $n$ & $\begin{array}{l}\text { Successful endo- } \\
\text { scope insertion, } \%\end{array}$ & $\begin{array}{l}\text { Successful } \\
\text { procedure, \% }\end{array}$ \\
\hline $1-10$ & 7 & 74.3 & 64.3 \\
$11-20$ & 7 & 82.9 & 74.3 \\
$21-30$ & 7 & 92.9 & 81.4 \\
$31-40$ & 7 & 94.3 & 92.9 \\
$41-50$ & 6 & 96.7 & 93.3 \\
$51-60$ & 6 & 95.0 & 91.4 \\
$61-70$ & 4 & 95.0 & 92.5 \\
$71-80$ & 3 & 96.7 & 96.7 \\
\hline
\end{tabular}

SBE-ERCP single-balloon-assisted enteroscopy endoscopic retrograde cholangiopancreatography

\section{Adverse Events}

The adverse events are shown in Table 5. The overall incidence of adverse events was $6.3 \%$ (43/687 procedures). The most frequent adverse event was pancreatitis $(1.7 \%$; $12 / 687$ procedures). All patients who developed pancreatitis had mild pancreatitis and were successfully treated with conservative therapy. Obvious perforation occurred in 10 patients $(1.5 \%)$. For five patients, emergency surgery was performed, and all patients recovered well. In the other five patients, the perforated part was clipped and conservatively treated until they had recovered. According to the reconstruction technique, the rates of adverse events were $9.8 \%$ in R-Y, $15.4 \%$ in B-II, $4.3 \%$ in $\mathrm{HJ} 4.5 \%$ in $\mathrm{HJ}, 5.9 \%$ in other
Table 5 Adverse events $(n=687$ procedures)

\begin{tabular}{lclllll}
\hline & Total & R-Y & B-II & PD & HJ & Others \\
& $n=687$ & 122 & 52 & 161 & 335 & 17 \\
\hline Pancreatitis, $n(\%)$ & $12(1.7)$ & 6 & 4 & 1 & 1 & 0 \\
Perforation, $n(\%)$ & $10(1.5)$ & 2 & 2 & 2 & 4 & 0 \\
Mucosal laceration, $n(\%)$ & $9(1.3)$ & 2 & 2 & 1 & 4 & 0 \\
Cholangitis, $n(\%)$ & $6(0.9)$ & 1 & 0 & 3 & 2 & 0 \\
Peritonitis & $3(0.4)$ & 0 & 0 & 0 & 3 & 0 \\
Biliary tract injury, $n(\%)$ & $1(0.1)$ & 0 & 0 & 0 & 1 & 0 \\
Air embolus, $n(\%)$ & $1(0.1)$ & 0 & 0 & 0 & 0 & 1 \\
Hemorrhage & $1(0.1)$ & 1 & 0 & 0 & 0 & 0 \\
Total, $n(\%)$ & $43(6.3)$ & $12(9.8)$ & $8(15.4)$ & $7(4.3)$ & $15(4.5)$ & $1(5.9)$ \\
$P$ value & & 0.058 & $0.004 *$ & 0.285 & 0.081 & 0.968 \\
\hline
\end{tabular}

$R-Y$ Roux-en-Y gastrectomy, $B$-II Billroth-II gastrectomy, $P D$ pancreaticoduodenectomy, $H J$ hepaticojejunostomy with Roux-en-Y

$* P<0.05$ 
techniques. In B-II reconstruction, the adverse event occurrence rate was significantly higher in B-II than in other techniques $(P=0.004)$.

\section{Result of the Seven Trainees According to Their Experience During the Study Period}

Based on our results, we set 30 cases as the borderline that delineated trainee from expert and compared the results in each period (Table 6). In the two groups, there was no difference in the surgical reconstruction methods. If the endoscopist was replaced and the procedure was successful, it was defined as a failure in this learning curve evaluation. There were no significant differences in insertion time, procedure time, and the incidence of adverse events; however, the endoscope insertion and procedure success rates were significantly higher in the expert period.

\section{Discussion}

This retrospective study investigated the learning curve of the SBE-ERCP procedure. Our findings indicate that performing $>30$ cases is one of the targets to become competent in performing SBE-ERCP in patients with a surgically altered anatomy. ERCP-related procedures using a balloon endoscope are especially useful and less invasive than percutaneous or surgical procedures to treat patients with pancreaticobiliary diseases who have a surgically altered anatomy. Many studies have examined the efficacy and safety of BAE-ERCP [10-13]. However, the BAE-ERCP procedure is technically challenging and requires extensive experience and skills specific to an endoscopist. Therefore, the success rate of BAE-ERCP varies by study and institution. For example, in a meta-analysis that examined double balloon enteroscopy-assisted ERCP [19], the integrated success rate of endoscope insertion was $89.7 \%$ (95\% CI 79.6-94.3\%); however, differences among the studies ranged from 69 to $100 \%$. In addition, the success rate of the procedures ranged from 42 to $81 \%$, while the integrated success rate was $63.5 \%$ (95\% CI 53.7-72.8\%). The major problem with the differences among these studies is that the number of cases varies among the reports. In addition, the improvement in the skills that endoscopists gained over time should be considered; however, the learning curve remained unknown. Therefore, we examined the learning curve of SBE-ERCP. Although there are currently no guidelines which state the minimum acceptable success rate for SBE-ERCP, we set a target success rate of $\geq 90 \%$. We considered that competent ERCP endoscopists should be able to cannulate the duct of interest in $>90 \%$ of ERCP procedures in patients with a normal gastrointestinal anatomy [16].

In our study, regarding endoscope insertion, a success rate of $>90 \%$ was achieved when endoscopists had performed 20 cases, and for each successful procedure, a success rate of $>90 \%$ was achieved when endoscopists had performed $>30$ cases. Comparing the results of the period before and after having performed 30 cases at the advanced level, the endoscope insertion and procedure success rates were significantly higher. Therefore, 30 cases might be an achievement point. In a previous study that examined learning curves, the number of cases to become a competent endoscopist in ERCP with a normal anatomy is defined as 200 cases [18]. All the endoscopists in this
Table 6 A comparison of outcomes between the number of SBE-ERCP cases below and above 30

\begin{tabular}{lccc}
\hline Number of SBE-ERCP cases & $\begin{array}{l}1-30 \text { cases } \\
(n=211)\end{array}$ & $\begin{array}{l}\text { More than 30 cases } \\
(n=476)\end{array}$ & $P$ value \\
\hline Surgical reconstruction methods, $n(\%)$ & & & \\
R-Y & $42(19.9)$ & $80(16.8)$ & 0.32 \\
B-II & $17(8.1)$ & $35(7.4)$ & 0.74 \\
PD & $56(26.5)$ & $105(22.1)$ & 0.20 \\
HJ & $94(44.5)$ & $241(50.6)$ & 0.14 \\
Others & $5(2.4)$ & $12(2.5)$ & 0.90 \\
Endoscope insertion success, $n(\%)$ & $182(86.3)$ & $436(91.6)$ & $0.032^{*}$ \\
Insertion time, mean, min & 23.8 & 20.4 & 0.081 \\
Procedural success, $n(\%)$ & $162(76.8)$ & $412(86.6)$ & $0.001 *$ \\
Procedure time, mean, min & 57.5 & 57.1 & 0.51 \\
Adverse event, $n(\%)$ & $11(5.2)$ & $29(6.1)$ & 0.65 \\
Switch to another endoscopist, $n(\%)$ & $49(23.2)$ & $64(13.4)$ & $0.001 *$ \\
\hline
\end{tabular}

$R-Y$ Roux-en-Y gastrectomy, $B$-II Billroth-II gastrectomy, $P D$ pancreaticoduodenectomy, $H J$ hepaticojejunostomy with Roux-en-Y, $S B E-E R C P$ Single-balloon-assisted enteroscopy endoscopic retrograde cholangiopancreatography

$* P<0.05$ 
study had already performed $>400$ ERCP cases and were, therefore, experts in ERCP. However, for all endoscopists, this was their first experience with SBE-ERCP. In a previous study that analyzed the learning curve of balloon enteroscopy in patients with a normal anatomy, 10 cases were required for oral insertion and 20 cases for trans-anal insertion [16]. SBE-ERCP is a combined procedure of balloon enteroscopy and ERCP; therefore, we initially estimated that approximately 10-20 cases would be required to become acquainted with the balloon enteroscopy technique. However, our study revealed that $>30$ cases were required. This is because SBE-ERCP requires a different technique compared to conventional enteroscopy. In fact, the learning curve of those who had experience with conventional enteroscopy was similar to that of all groups. The ability to handle various difficult cases, such as selective endoscope intubation into the afferent loop, intestinal adhesions, identification of papilla, selective cannulation, and limitations of conventional ERCP instruments for the balloon enteroscope, is necessary. To manage these difficulties and increase the success rate of the procedure, our institution employs several techniques. For example, the SBE is a forward-viewing endoscope without an elevator function; thus, cannulation with SBE into a native papilla is technically difficult. Placing the papilla in an adequate position and maintaining its stability are challenging tasks for a trainee endoscopist. In cases where the papilla is in a tangential position relative to the endoscope, and there is an insufficient distance between the papilla and the endoscope, a retro-reflex position [20], such as a $\mathrm{J}$-turn position, is effective. Moreover, a soft transparent plastic cap may be useful to assist in visualizing or steadying the native papilla for cannulation (Fig. 2. cap-assisted cannulation technique) [21,22]. When selective biliary cannulation has failed, a precut technique is performed using a needle-knife (HF needle, length $250 \mathrm{~cm}$; MTWEndoskopie, Wesel, Germany). These techniques can be performed after approximately 30 BAE-ERCP cases.

The overall incidence of adverse events was $6.3 \%$. The complication rate of BAE-ERCP was reported to be $6.27 \%$ (95\% CI 2.61-11.38\%) by meta-analyses [23]. Therefore, our results seem to be within the acceptable range. The adverse events in our study occurred evenly throughout the learning curve. The frequency of adverse events differed depending on the surgical technique (Table 5). This finding suggests that patient factors may have a greater influence on adverse events than endoscopist factors. Other studies $[24,25]$ indicate that B-II reconstruction is associated with a high risk of complications in BAE-ERCP because of the prevalence of naïve papilla cases and the anatomical reason of the short and tight distance between the Treitz ligament and the gastro-jejunal anastomosis. Therefore, BAE-ERCP procedures in patients with B-II reconstruction should be performed with caution.
Fig. 2 Cap-assisted cannulation technique. A Complete observation of the ampulla of Vater by use of a cap in single-balloon enteroscopy. B In this view, the axis of the bile duct is tangential to the catheter (dashed arrow); it is difficult to cannulate to the bile duct. C First, the distance of the catheter tip and cap is kept constant. Next, by hooking the papilla with a cap by endoscopic manipulation, it becomes possible to align the bile duct axis and cannulate. D Successful cholangiography

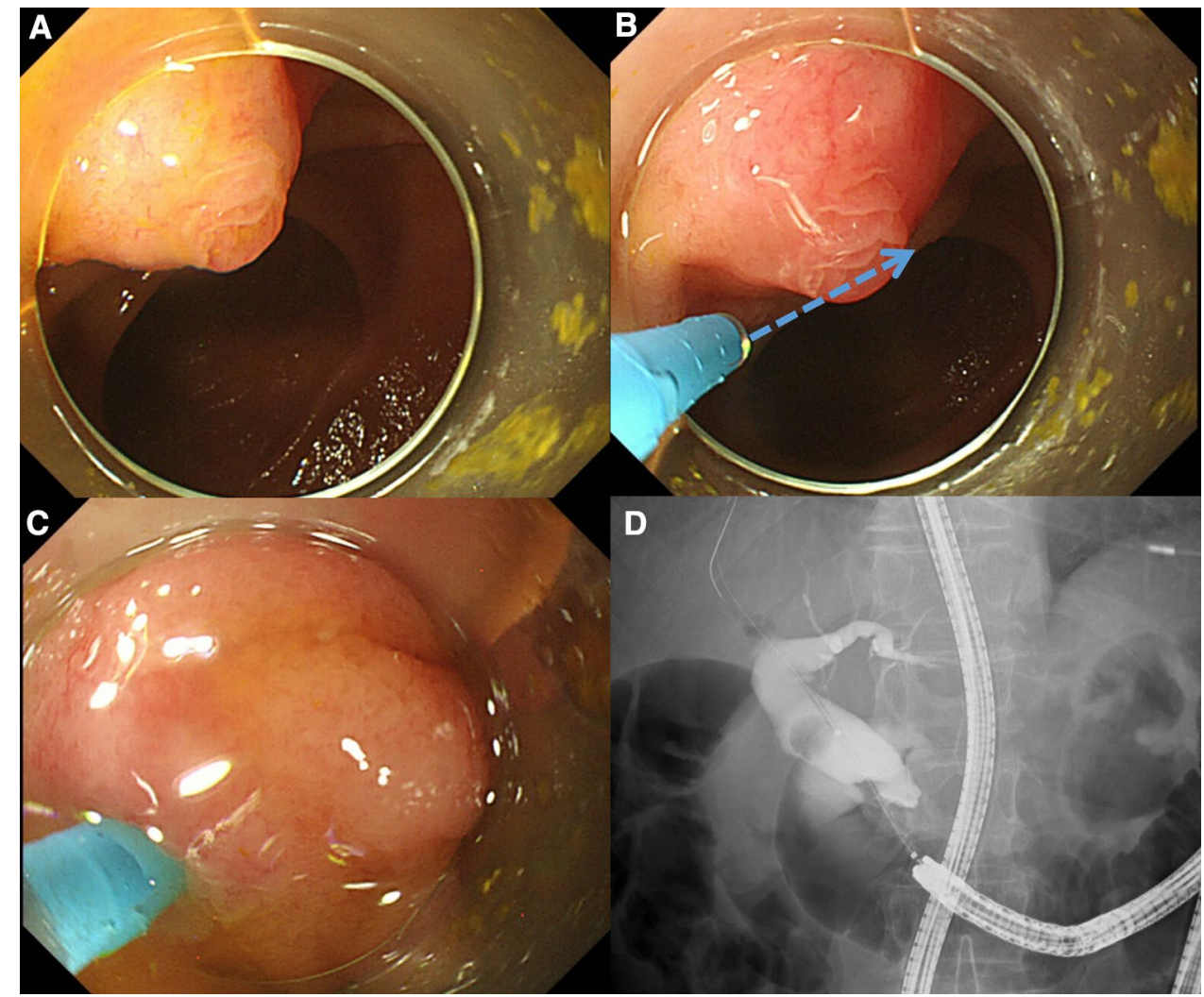


There are several limitations to this study. The first is that it is a retrospective, observational case series study, and bias cannot be completely ruled out due to the varying difficulties of each case. The problem with non-randomized case series data is that the different mix of cases treated by each endoscopist can potentially conceal the true learning effects. Consequently, we have mitigated this issue by using several mixed case series of 10 cases for each endoscopist, referring to the methods of the moving average analysis [26]. The second limitation is that this is a single-center study. The success of each procedure was subject to interpretation; increased confidence gained during our experience could have led to the perceived increase in the success of the procedure. Despite these limitations, to our knowledge, our study included many cases $(>680)$ compared to other studies, and we analyzed the results of seven different endoscopists. The third limitation is that this study used only an SBE. Currently, there is also a double-balloon endoscope as a balloon-assisted endoscope; however, it has been reported that the endoscope insertion rate and procedure success rate of both are almost similar [27]. Another limitation of this study is that not all trainees had the opportunity to perform $>100$ SBE-ERCP cases during formal training. Further studies with more cases are required in the future.

\section{Conclusion}

This is the first study that evaluated the SBE-ERCP learning curve for endoscopists. Our data showed that the success rates of endoscope insertion and procedure increased with increasing experience in ERCP in patients with a surgically altered anatomy, reaching $>90 \%$ in 20 cases for insertion, and $>90 \%$ in $>30$ cases for the procedure. These results suggest that performing $>30$ cases is one of the targets to become competent in performing SBE-ERCP.

Funding The study was supported by a grant from the Ministry of Education, Culture, Sports, Science and Technology, Japan (KIBANC: 18K08011).

\section{Declarations}

Conflict of interest The authors declare that they have no conflict of interest.

Ethics approval This study complied with the Declaration of Helsinki and was approved by the Research Ethics Committee of The Yokohama City University (Approval number: B191200004).

Consent to participate From all patients, written informed consent was obtained prior to the procedure.
Open Access This article is licensed under a Creative Commons Attribution-NonCommercial 4.0 International License, which permits any non-commercial use, sharing, adaptation, distribution and reproduction in any medium or format, as long as you give appropriate credit to the original author(s) and the source, provide a link to the Creative Commons licence, and indicate if changes were made. The images or other third party material in this article are included in the article's Creative Commons licence, unless indicated otherwise in a credit line to the material. If material is not included in the article's Creative Commons licence and your intended use is not permitted by statutory regulation or exceeds the permitted use, you will need to obtain permission directly from the copyright holder. To view a copy of this licence, visit $\mathrm{http} / / /$ creativecommons.org/licenses/by-nc/4.0/.

\section{References}

1. Freeman ML, Guda NM. ERCP cannulation: a review of reported techniques. Gastrointest Endosc 2005;61:112-125.

2. Hintze RE, Adler A, Veltzke W, Abou-Rebyeh H. Endoscopic access to the papilla of Vater for endoscopic retrograde cholangiopancreatography in patients with billroth II or Roux-en-Y gastrojejunostomy. Endoscopy 1997;29:69-73.

3. Wright BE, Cass OW, Freeman ML. ERCP in patients with longlimb Roux-en-Y gastrojejunostomy and intact papilla. Gastrointest Endosc 2002;56:225-232.

4. Elton E, Hanson BL, Qaseem T, Howell DA. Diagnostic and therapeutic ERCP using an enteroscope and a pediatric colonoscope in long-limb surgical bypass patients. Gastrointest Endosc 1998;47:62-67.

5. Haber GB. Double balloon endoscopy for pancreatic and biliary access in altered anatomy (with videos). Gastrointest Endosc 2007;66:S47-S50.

6. Chu YC, Su SJ, Yang CC, Yeh YH, Chen CH, Yueh SK. ERCP plus papillotomy by use of double-balloon enteroscopy after Billroth II gastrectomy. Gastrointest Endosc 2007;66:1234-1236.

7. Feitoza AB, Baron TH. Endoscopy and ERCP in the setting of previous upper GI tract surgery. Part II: postsurgical anatomy with alteration of the pancreaticobiliary tree. Gastrointest Endosc 2002;55:75-79.

8. Park JS, Kim MH, Lee SK et al. Efficacy of endoscopic and percutaneous treatments for biliary complications after cadaveric and living donor liver transplantation. Gastrointest Endosc 2003;57:78-85.

9. Haruta H, Yamamoto H, Mizuta K et al. A case of successful enteroscopic balloon dilation for late anastomotic stricture of choledochojejunostomy after living donor liver transplantation. Liver Transpl 2005;11:1608-1610.

10. Shimatani M, Matsushita M, Takaoka M et al. Effective "short" double-balloon enteroscope for diagnostic and therapeutic ERCP in patients with altered gastrointestinal anatomy: a large case series. Endoscopy 2009;41:849-854.

11. Raithel M, Dormann H, Naegel A et al. Double-balloon-enteroscopy-based endoscopic retrograde cholangiopancreatography in post-surgical patients. World J Gastroenterol 2011;17:2302-2314.

12. Siddiqui AA, Chaaya A, Shelton $\mathrm{C}$ et al. Utility of the short double-balloon enteroscope to perform pancreaticobiliary interventions in patients with surgically altered anatomy in a US multicenter study. Dig Dis Sci 2013;58:858-864. https://doi.org/10. 1007/s10620-012-2385-z.

13. Azeem N, Tabibian JH, Baron $\mathrm{TH}$ et al. Use of a single-balloon enteroscope compared with variable-stiffness colonoscopes for endoscopic retrograde cholangiography in liver transplant patients with Roux-en-Y biliary anastomosis. Gastrointest Endosc 2013;77:568-577. 
14. Liu K, Joshi V, Saxena P, Kaffes AJ. Predictors of success for double balloon-assisted endoscopic retrograde cholangiopancreatography in patients with Roux-en-Y anastomosis. Dig Endosc 2017;29:190-197.

15. Shimatani M, Hatanaka H, Kogure $\mathrm{H}$ et al. Diagnostic and therapeutic endoscopic retrograde cholangiography using a short-type double-balloon endoscope in patients with altered gastrointestinal anatomy: a multicenter prospective study in Japan. Am J Gastroenterol 2016;111:1750-1758.

16. ASGE Standards of Practice Committee, Faulx AL, Lightdale JR et al. Guidelines for privileging, credentialing, and proctoring to perform GI endoscopy. Gastrointest Endosc. 2017;85:273-281.

17. Cotton PB, Eisen GM, Aabakken L et al. A lexicon for endoscopic adverse events: report of an ASGE workshop. Gastrointest Endosc 2010;71:446-454.

18. Yane K, Katanuma A, Maguchi H et al. Short-type single-balloon enteroscope-assisted ERCP in postsurgical altered anatomy: potential factors affecting procedural failure. Endoscopy 2017;49:69-74.

19. Ekkelenkamp VE, Koch AD, Rauws EA, Borsboom GJ, de Man RA, Kuipers EJ. Competence development in ERCP: the learning curve of novice trainees. Endoscopy 2014;46:949-955.

20. Ishii K, Itoi T, Tonozuka R et al. Balloon enteroscopy-assisted ERCP in patients with Roux-en-Y gastrectomy and intact papillae (with videos). Gastrointest Endosc 2016;83:377-386.e6.

21. Choi YR, Han JH, Cho YS et al. Efficacy of cap-assisted endoscopy for routine examining the ampulla of Vater. World J Gastroenterol 2013;19:2037-2043.

22. Trindade AJ, Mella JM, Slattery E et al. Use of a cap in singleballoon enteroscopy-assisted endoscopic retrograde cholangiography. Endoscopy 2015;47:453-456.
23. Shao XD, Qi XS, Guo XZ. Endoscopic retrograde cholangiopancreatography with double balloon enteroscope in patients with altered gastrointestinal anatomy: a meta-analysis. Saudi J Gastroenterol 2017;23:150-160.

24. Takano S, Fukasawa M, Shindo H et al. Risk factors for perforation during endoscopic retrograde cholangiopancreatography in post-reconstruction intestinal tract. World J Clin Cases 2019;7:10-18.

25. Tokuhara M, Shimatani M, Mitsuyama T et al. Evaluation of complications after endoscopic retrograde cholangiopancreatography using a short type double balloon endoscope in patients with altered gastrointestinal anatomy: a single-center retrospective study of 1,576 procedures. J Gastroenterol Hepatol 2020;35:1387-1396.

26. Ward ST, Mohammed MA, Walt R, Valori R, Ismail T, Dunckley P. An analysis of the learning curve to achieve competency at colonoscopy using the JETS database. Gut 2014;63:1746-1754.

27. Skinner M, Popa D, Neumann H, Wilcox CM, Mönkemüller K. ERCP with the overtube-assisted enteroscopy technique: a systematic review. Endoscopy 2014;46:560-572.

Publisher's Note Springer Nature remains neutral with regard to jurisdictional claims in published maps and institutional affiliations. 